\title{
Core-shell nanostructured hybrid composites for volatile organic compound detection
}

\author{
This article was published in the following Dove Press journal: \\ International Journal of Nanomedicine \\ 28 August 2015 \\ Number of times this article has been viewed
}

\author{
Tran Thanh Tung ${ }^{1,2}$ \\ Dusan Losic' \\ Seung Jun Park \\ Jean-Francois Feller ${ }^{2}$ \\ TaeYoung Kim ${ }^{3}$ \\ 'School of Chemical Engineering, \\ The University of Adelaide, North \\ Terrace, Adelaide, SA, Australia; \\ ${ }^{2}$ Smart Plastics Group, European \\ University of Brittany (UEB), LIMATB- \\ UBS, Lorient, France; ${ }^{3}$ Department \\ of Bionanotechnology, Gachon \\ University, Sujeong-gu, Seongnam-si, \\ Gyeonggi-do South Korea
}

\begin{abstract}
We report a high-performance chemiresistive sensor for detection of volatile organic compound (VOC) vapors based on core-shell hybridized nanostructures of $\mathrm{Fe}_{3} \mathrm{O}_{4}$ magnetic nanoparticles (MNPs) and poly(3,4-ethylenedioxythiophene) (PEDOT)-conducting polymers. The MNPs were prepared using microwave-assisted synthesis in the presence of polymerized ionic liquids (PILs), which were used as a linker to couple the MNP and PEDOT. The resulting PEDOT-PIL-modified $\mathrm{Fe}_{3} \mathrm{O}_{4}$ hybrids were then explored as a sensing channel material for a chemiresistive sensor to detect VOC vapors. The PEDOT-PIL-modified $\mathrm{Fe}_{3} \mathrm{O}_{4}$ sensor exhibited a tunable response, with high sensitivity (down to a concentration of $1 \mathrm{ppm}$ ) and low noise level, to VOCs; these VOCs include acetone vapor, which is present in the exhaled breath of potential lung cancer patients. The present sensor, based on the hybrid nanostructured sensing materials, exhibited a $38.8 \%$ higher sensitivity and an $11 \%$ lower noise level than its PEDOTPIL-only counterpart. This approach of embedding MNPs in conducting polymers could lead to the development of new electronic noses, which have significant potential for the use in the early diagnosis of lung cancer via the detection of VOC biomarkers.
\end{abstract}

Keywords: hybrid nanomaterials, nanoparticle, conducting polymer, electronic nose, lung cancer detection

\section{Introduction}

The early and accurate detection of lung cancer is essential to the effective treatment of patients and reduction of the mortality rate associated with the cancer disease. ${ }^{1-5}$ Among various detection methods, breath analysis has attracted significant attention owing to its noninvasive nature and simplicity. This method also has the potential to diagnose lung cancer at an early stage by detecting volatile organic compound (VOC) biomarkers in exhaled breath. ${ }^{6-9}$ As such, a number of breath-analysis tools have been developed including gas chromatography/mass spectrometry, ${ }^{10-14}$ ion flow tube mass spectrometry, ${ }^{15,16}$ chemo-luminescence sensors, ${ }^{17}$ optochemical fibers, ${ }^{18}$ infrared spectroscopy, ${ }^{19}$ and polymer-coated surface acoustic wave sensors. ${ }^{20}$ Incorporating most of the conventional breath analysis techniques into portable sensing devices is difficult, however, owing to the bulky and expensive nature of these instruments and complexity of their operation. ${ }^{21,22}$ Furthermore, these methods often require a presampling step to increase the relative concentration of breath VOCs to detectable levels. ${ }^{2,23}$ Therefore, the development of highly efficient, sensitive, simple, inexpensive, and reliable breath sensing devices is essential for early diagnosis of cancer disease by breath analysis.

A chemiresistive sensor, also referred to as an electronic nose is portable, fast, noninvasive, and highly responsive to various $\operatorname{VOCs}^{2,9,24}$ and constitutes a robust and cost-effective solution for VOC detection. These sensors rely on changes in the electrical resistance of channel materials arising from their interaction with VOC biomarkers. 
Developing a channel material that can efficiently interact with the VOC molecules in the exhaled breath is crucial. Efficient channel materials should rapidly adsorb/desorb the target analytes, and exhibit high sensitivity and stability (ie, low noise level) in their presence. Chemiresistive sensors have been fabricated from various channel materials including metal oxides, ${ }^{25-27}$ intrinsically conducting polymers, ${ }^{28-31}$ functionalized carbon nanomaterials or nanocomposites, ${ }^{32-35}$ and quartz crystal microbalance. Nanomaterials are considered as efficient channel materials with excellent sensing capability, owing to their unique nanoscale features and high surface-to-volume ratio. ${ }^{36,37}$ For example, metal or metal oxide nanoparticles used as channel materials showed an improved sensitivity to specific analyte molecules. ${ }^{38-41}$ However, these nanoparticle-based sensors need further improvement in terms of sensitivity, selectivity, and stability for their practical use in applications. This can be achieved through added functionalities of hybrid nanomaterials that combine inorganic nanoparticles and organic molecules. ${ }^{42,43}$ In this regard, core-shell-structured hybrid materials of magnetic nanoparticles (MNPs) $\left(\mathrm{eg}, \mathrm{Fe}_{3} \mathrm{O}_{4}\right)$ and conducting polymers (eg, poly (3,4-ethylenedioxythiophene) [PEDOT], ${ }^{44}$ polyaniline $[\mathrm{PANi}],{ }^{45,46}$ and polypyrrole $[\mathrm{PPy}]^{47,48}$ ) are especially promising sensing materials owing to their synergistic effect. These hybrid materials have been used for a number of applications including drug delivery, sensors, wastewater treatment, energy storage, and catalysts.
Herein, we propose a highly sensitive and stable chemiresistive sensor based on core-shell nanostructured hybrid materials consisting of MNPs and conducting polymers. The hybrid materials consisted of $\mathrm{a} \mathrm{Fe}_{3} \mathrm{O}_{4}$ core surrounded by a PEDOT shell; a polymerized ionic liquid (PIL) was used as a linker to couple the core and shell materials. Coupling the PEDOT and $\mathrm{Fe}_{3} \mathrm{O}_{4}$ via the PIL-mediated process yielded the core-shell nanostructured PEDOT-PIL-modified $\mathrm{Fe}_{3} \mathrm{O}_{4}$ (PIL@ $\mathrm{Fe}_{3} \mathrm{O}_{4}$ ) hybrid materials. The hybrid material was then used as an active sensing material for the detection of various VOC molecules. The synthesis of core-shell hybrid nanostructures of PEDOT-PIL@ $\mathrm{Fe}_{3} \mathrm{O}_{4}$ and sensing device are illustrated in Figure 1. PIL is expected to play multiple roles in the microwave synthesis of $\mathrm{Fe}_{3} \mathrm{O}_{4}$ nanoparticles. For example, they: 1) consist entirely of highly polarizable ions that absorb microwaves efficiently, thereby resulting in improved yields of products; 2) act as a stabilizer for the $\mathrm{Fe}_{3} \mathrm{O}_{4}$ nanoparticles and prevent their aggregation in the solution; and 3) function as a surface-functionalizing material that imparts specific functionalities to the surfaces of $\mathrm{Fe}_{3} \mathrm{O}_{4}$ nanoparticles for efficient hybridization with conducting polymers. The sensor arrays based on the hybrid PEDOTPIL@ $\mathrm{Fe}_{3} \mathrm{O}_{4}$ channel materials exhibited high sensitivity (1 ppm concentration) to VOC biomarkers including methanol, ethanol, acetone, benzene, and toluene, which are present in the exhaled breath of lung cancer patients. ${ }^{6-9}$ The sensors also exhibited a high stability with a low level of noise,

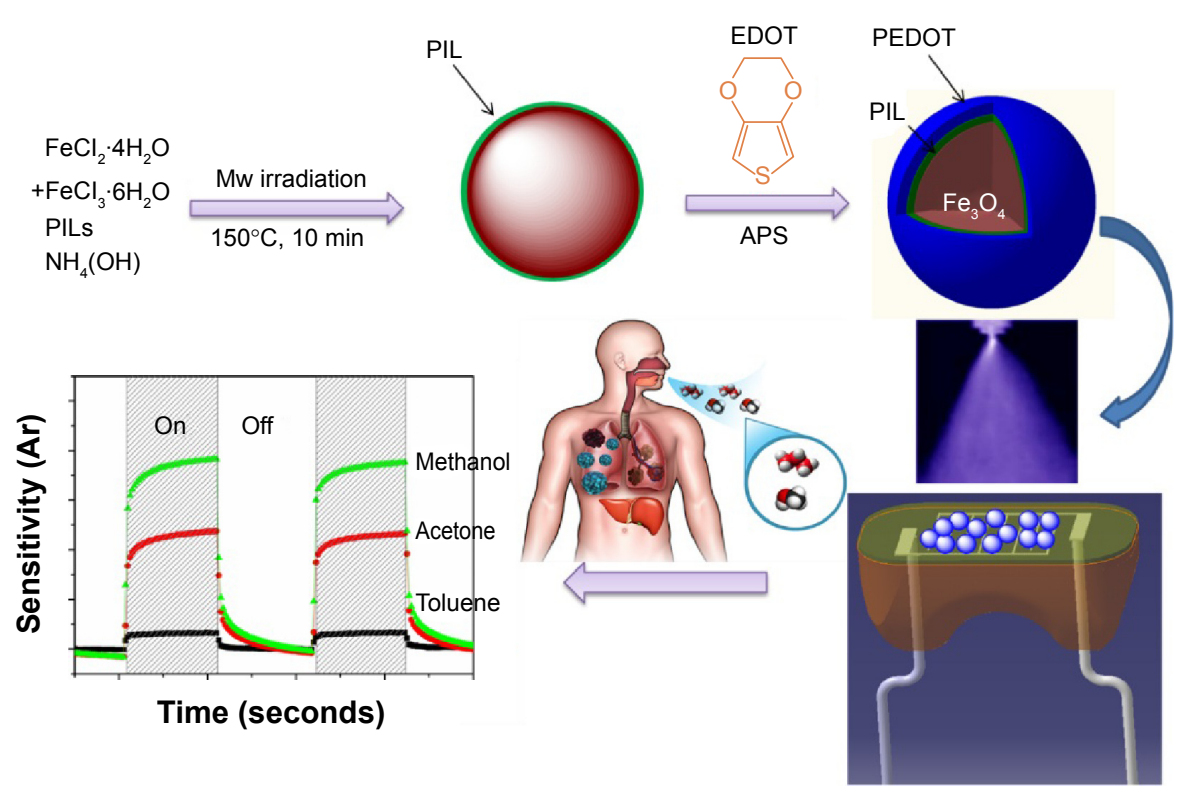

Figure I Schematics of the synthesis of core-shell PEDOT-PIL@Fe $\mathrm{O}_{4}$ hybrid, and its application in chemiresistive sensor for detection of lung cancer VOCs.

Note: The human body photo was adapted with permission from Hakim M, Broza YY, Barash O, et al. Volatile organic compounds of lung cancer and possible biochemical pathways. Chem Rev. 2012;1 I (I I)2:5949.65 Copyright (C) 2012 American Chemical Society.

Abbreviations: APS, ammonium persulfate; Ar, relative amplitude of the electrical signals; Mw, microwave; min, minute; PEDOT, poly(3,4-ethylenedioxythiophene); PIL, polymerized ionic liquid; VOCs, volatile organic compounds; EDOT, 3,4-ethylenedioxythiophene. 
indicative of the high reliability of the sensing channels. The results suggest that the sensors based on PEDOT-PIL $@ \mathrm{Fe}_{3} \mathrm{O}_{4}$ channel materials have significant potential for applications, including the point of care diagnostics and early diagnosis of cancer disease, via the detection of biomarkers.

\section{Experiment}

\section{Materials}

Iron(II) chloride tetrahydrate ( $>99.0 \%$ ), iron(III) chloride hexahydrate (ACS reagent, 97\%), bromoethane (98\%), 1-vinylimidazole (99\%), and azobis(2-methylpropionitrile) (99\%) were purchased from Sigma-Aldrich (St Louis, MO, USA) and used without further purification. Ammonium persulfate (APS) (98\%) and ammonia solution (28\%) were purchased from Tokyo Chemical Industry (TCI) Chemicals (Tokyo, Japan). Methanol (99\%), ethanol (98\%), acetone (98\%), benzene $(98 \%)$, toluene $(99.8 \%)$, and chloroform $(99.5 \%)$ were used as purchased.

\section{Microwave-assisted synthesis of $\mathrm{Fe}_{3} \mathrm{O}_{4}$ nanoparticles}

PIL of poly(1-vinyl-3-ethylimidazolium) salts bearing the anion $\left(\mathrm{Br}^{-}\right)$was synthesized in accordance with a previously reported procedure. ${ }^{49,50}$ For the preparation of PILstabilized magnetic nanocrystals, an aqueous solution of PIL (200 mg) was slowly added, under vigorous stirring, to a mixed solution of $\mathrm{FeCl}_{2} \cdot 4 \mathrm{H}_{2} \mathrm{O}(0.2 \mathrm{~g}$ in $5 \mathrm{~mL}$ of $0.5 \mathrm{M}$ $\mathrm{HCl})$ and $\mathrm{FeCl}_{3} \cdot 6 \mathrm{H}_{2} \mathrm{O}(0.54 \mathrm{~g}$ in $10 \mathrm{~mL}$ water $)$ at room temperature. After 15 minutes, $16 \mathrm{~mL}$ of ammonium hydroxide solution was added dropwise for 10 minutes. This mixture was then loaded into a tube, and placed inside a microwave reactor. The microwave reactor (MARS; CEM corporation, Matthews, NC, US) was operated at a power and pressure of $800 \mathrm{~W}$ and 4,000,000 $\mathrm{Pa}$, respectively, and irradiated at $150^{\circ} \mathrm{C}$ for 10 minutes under continuous stirring. The darkbrown precipitate, ie, $\mathrm{PIL} @ \mathrm{Fe}_{3} \mathrm{O}_{4}$, was obtained by removing the supernatant and washing repeatedly with water.

\section{Synthesis of PEDOT-PIL@ $\mathrm{Fe}_{3} \mathrm{O}_{4}$ nano- composites}

PEDOT was formed on the surface of the $\mathrm{Fe}_{3} \mathrm{O}_{4}$ MNPs by oxidative in situ polymerization of EDOT in the presence of PIL@ $\mathrm{Fe}_{3} \mathrm{O}_{4}$. An oxidizing agent, APS, was then added to the mixture containing the EDOT and PIL@ $\mathrm{Fe}_{3} \mathrm{O}_{4}$ followed by 24 hours' reaction under vigorous stirring at room temperature. The polymerization of EDOT on the $\mathrm{Fe}_{3} \mathrm{O}_{4}$ surface was initiated when APS was added to a mixture of PIL@ $\mathrm{Fe}_{3} \mathrm{O}_{4}$ and EDOT monomer. The PIL on the $\mathrm{Fe}_{3} \mathrm{O}_{4}$ surface provided efficient linkage between the PEDOT and the $\mathrm{Fe}_{3} \mathrm{O}_{4}$ and was therefore used as a polymerization template for the PEDOT, from which hybrid core-shell-structured PEDOT-PIL@ $\mathrm{Fe}_{3} \mathrm{O}_{4}$ composites were obtained. The PEDOT-PIL@ $\mathrm{Fe}_{3} \mathrm{O}_{4}$ products were washed repeatedly with deionized water and ethanol in order to remove unreacted species (eg, EDOT, freely suspended PIL molecules, APS) from the products. For the sake of comparison, the PILdoped PEDOT (PEDOT-PIL) without $\mathrm{Fe}_{3} \mathrm{O}_{4}$ nanoparticles was also prepared under the same synthetic condition.

\section{Preparation and characterization of sensing device}

Sensor arrays were fabricated via spray layer-by-layer deposition onto interdigitated electrodes composed of $25 \%$ $\mathrm{Ag} / 75 \% \mathrm{Pd}$ tracks, separated by a $15 \mu \mathrm{m}$ ceramic gap, and prepared by cleaving $22 \mathrm{nF}$ capacitors. The electrode surface was rendered contaminant-free by polishing and then cleaning with ethanol. The spray layer-by-layer deposition device was equipped with a spray valve controller that allowed for precise control of the nozzle scanning speed $\left(\mathrm{Vs}=50 \mathrm{~mm} \cdot \mathrm{s}^{-1}\right)$, solution flow rate, air pressure $(0.1 \mathrm{MPa})$, and target-to-nozzle distance $(8 \mathrm{~cm})$. After fabrication, the vapor sensors were conditioned overnight at $30^{\circ} \mathrm{C}$ in a controlled atmosphere.

\section{Characterization}

Structure and morphology of the PIL $@ \mathrm{Fe}_{3} \mathrm{O}_{4}$ and PEDOTPIL@ Fe $_{3} \mathrm{O}_{4}$ samples were characterized by a Hitachi S-4800 scanning electron microscope and a TECNAI 20 transmission electron microscope (TEM) equipped with an energy dispersive X-ray fluorescence spectrometer for energy-dispersive $\mathrm{X}$-ray analysis. To characterize the crystal structure, X-ray diffraction measurements were performed at $2 \theta$ values of $20^{\circ}-80^{\circ}$ and a step size of $0.02^{\circ}$, using a Bruker D8 advance diffractometer. In order to examine the chemical composition, X-ray photoelectron spectroscopy (XPS) measurements were performed with a VG Microtech ESCA2000 using monochromatic $\mathrm{Al} \mathrm{K} \alpha$ radiation $(\mathrm{hv}=1,486.6 \mathrm{eV}$ ). Atomic force microscopy (AFM) was performed in tapping mode with an AFM XE-100. Specimens for AFM study were prepared by drop-casting $\mathrm{Fe}_{3} \mathrm{O}_{4} @$ PIL-PEDOT suspension onto a silicon wafer and drying in a vacuum.

The chemiresistive property of the sensor was determined by recording the electrical responses of specimens during successive 5-minute rectangular pulses of VOC and pure nitrogen flows. Sensors were mounted in a vapor-sensing chamber and exposed at room temperature to saturated VOC analytes including ethanol, methanol, acetone, benzene, and 
toluene. The mass flow controllers were used to regulate the flow rate of the pure nitrogen and the solvent vapors. In addition, the electrical valves were controlled by a program developed under the Labview software. The sensing device was operated at room temperature, and the total flow rate was kept constant at $100 \mathrm{~cm}^{3} \cdot \mathrm{min}^{-1}$ during the measurements. Furthermore, the electrical conductivities of the conductive polymer composite (CPC)-based sensors were recorded with a Keithley 6517A multimeter and these sensors were placed in a $100 \times 10 \times 3 \mathrm{~mm}$ chamber during the dynamic vapor sensing measurements. The chemiresistive response of the CPC sensors is determined from the relative amplitude of the electrical signals $\left(A_{R}\right) \cdot A_{R}$ is the ratio of the change in resistance upon exposure to solvent vapors, normalized by the initial resistance of the sensor, as indicated in Equation 1:

$$
A_{R}=\frac{R-R_{O}}{R_{O}}
$$

where $R$ is the resistance of the sensing materials when exposed to analyte vapors and $R_{O}$ is the initial resistance when exposed to a nitrogen flow.

\section{Results and discussion}

The $\mathrm{Fe}_{3} \mathrm{O}_{4}$ MNPs were prepared in the presence of PIL by microwave-assisted synthetic method, in which microwave irradiation led to the rapid formation of PIL@ $\mathrm{Fe}_{3} \mathrm{O}_{4}$ nanoparticles. Figure 2 shows the field-emission scanning electron microscopy images of the PIL@ $\mathrm{Fe}_{3} \mathrm{O}_{4}$ (Figure 2A) and PEDOT-PIL@ $\mathrm{Fe}_{3} \mathrm{O}_{4}$ (Figure 2D) powder samples. These images reveal that the PEDOT-PIL@ $\mathrm{Fe}_{3} \mathrm{O}_{4}$ nanoparticles are larger than the PIL@ $\mathrm{Fe}_{3} \mathrm{O}_{4}$ ones, indicating PEDOT-layer-encapsulation of the $\mathrm{Fe}_{3} \mathrm{O}_{4}$ nanoparticles. Furthermore, the TEM images of PIL@ $\mathrm{Fe}_{3} \mathrm{O}_{4}$ (Figure 2B and $\mathrm{C}$ ) revealed that a thin (ie, with thickness on the order of nanometers) layer of PIL formed on the surface of the $\sim 10 \mathrm{~nm}$ sized $\mathrm{Fe}_{3} \mathrm{O}_{4}$ MNPs. The PIL molecules act as a stabilizer that prevents the aggregation of $\mathrm{Fe}_{3} \mathrm{O}_{4}$ nanoparticles in the suspension, and provide functionality for the polymerization with PEDOT on the surface of the $\mathrm{Fe}_{3} \mathrm{O}_{4}$. Furthermore, the TEM images of the PEDOTPIL@ $\mathrm{Fe}_{3} \mathrm{O}_{4}$ (Figure 2E and F) indicated that the core $\mathrm{Fe}_{3} \mathrm{O}_{4}$, which consists of particles with sizes of $\sim 15 \mathrm{~nm}$, is covered by PEDOT layers. The driving force for the hybridization of PEDOT and PIL@ $\mathrm{Fe}_{3} \mathrm{O}_{4}$ was explained in a previous study; ${ }^{49}$ ie, the PIL on the surface of the $\mathrm{Fe}_{3} \mathrm{O}_{4}$ nanoparticles functions as a charge balancing stabilizer to the positively doped PEDOT chains during the polymerization process. The AFM images of PEDOT-PIL@ $\mathrm{Fe}_{3} \mathrm{O}_{4}$ in Figure S1 showed that the measured particle sizes are consistent with those observed by TEM. The formation of MNPs via microwave irradiation was confirmed by X-ray diffraction measurement, as shown in Figure S2. The magnetic property of the PIL@ $\mathrm{Fe}_{3} \mathrm{O}_{4}$ was also examined by measuring
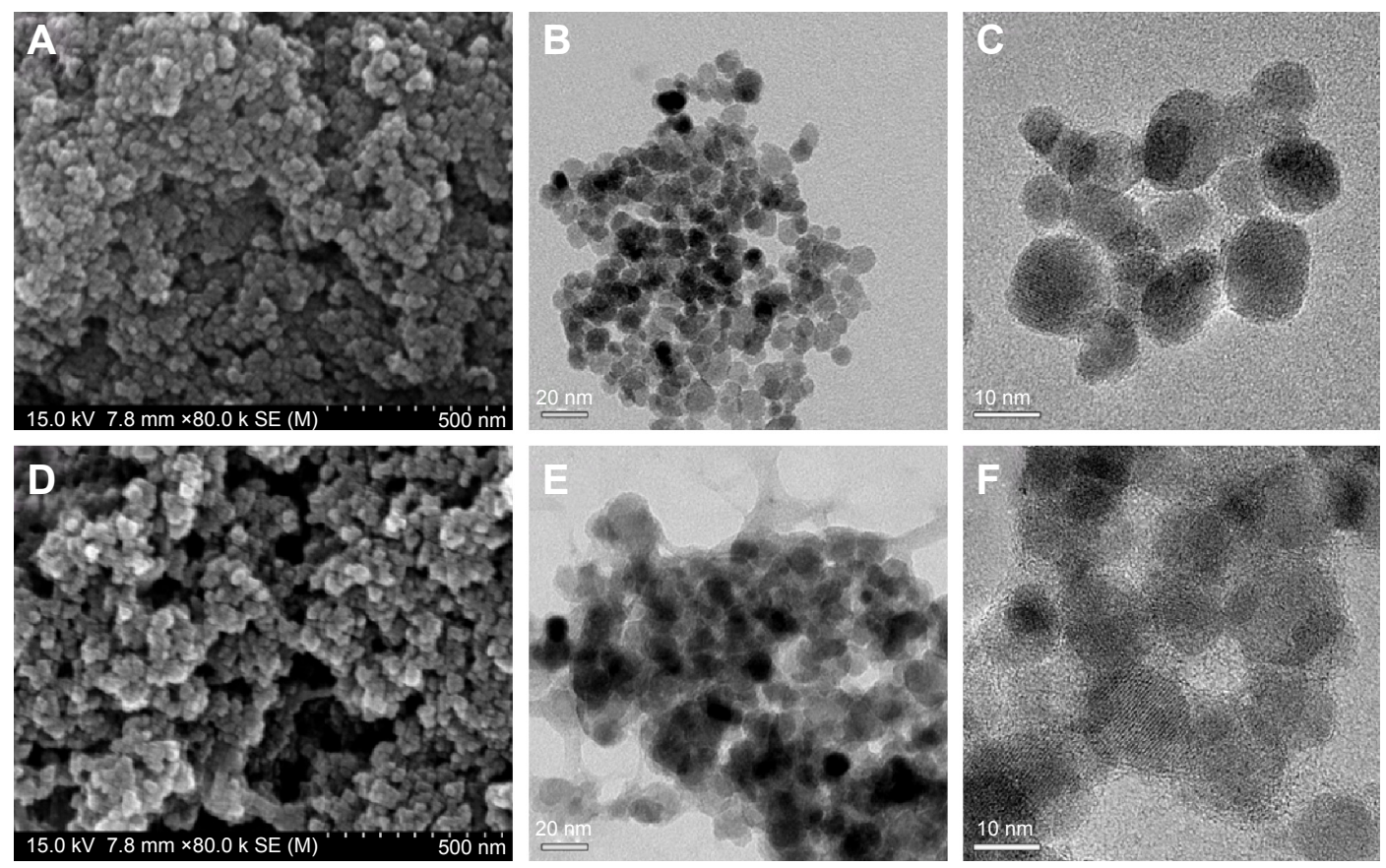

Figure 2 SEM and TEM images of the (A-C) PIL@Fe $\mathrm{O}_{4}$ and (D-F) PEDOT-PIL@Fe $\mathrm{O}_{4}$ composites.

Abbreviations: PEDOT, poly(3,4-ethylenedioxythiophene); PIL, polymerized ionic liquid; SEM, scanning electron microscopy; TEM, transmission electron microscopy. 
magnetization as a function of an external magnetic field at $300 \mathrm{~K}$. The magnetic hysteresis loop (Figure S3) shows nonlinear and reversible characteristics without remanence or coercivity, which implies that the PIL@ $\mathrm{Fe}_{3} \mathrm{O}_{4}$ exhibits superparamagnetic behavior. ${ }^{51}$ The magnetic property of the PIL@ $\mathrm{Fe}_{3} \mathrm{O}_{4}$ may play the role of improving device performance, especially by depressing the noise of sensing signal which will be discussed later.

The chemical composition of the resulting PIL@ $\mathrm{Fe}_{3} \mathrm{O}_{4}$ nanoparticles and PEDOT-PIL $@ \mathrm{Fe}_{3} \mathrm{O}_{4}$ hybrids were characterized by XPS. Figure 3 shows the XPS spectra of the PIL@ $\mathrm{Fe}_{3} \mathrm{O}_{4}$ (Figure 3A and B) and the PEDOT-PIL $@ \mathrm{Fe}_{3} \mathrm{O}_{4}$ (Figure $3 \mathrm{C}$ and $\mathrm{D}$ ). The Fe $2 \mathrm{p}$ (Figure $3 \mathrm{~A}$ ) and $\mathrm{N} 1 \mathrm{~s}$ spectra (Figure 3B) exhibited peaks corresponding to the $\mathrm{Fe}_{3} \mathrm{O}_{4}$ nanoparticles and the imidazolium ring in the PIL, respectively; this ring confirmed the presence of PIL molecules on $\mathrm{Fe}_{3} \mathrm{O}_{4}$ nanoparticles. In addition, the peak at $169 \mathrm{eV}$ in the $\mathrm{S} 2 \mathrm{p}$ spectrum (Figure $3 \mathrm{C}$ ) is associated with the $\mathrm{S}_{2} \mathrm{O}_{8}^{-}$ anion of the APS oxidant, and those at 164 and $165 \mathrm{eV}$ are attributed to the spin-split doublets of sulfur atoms in the PEDOT backbone. ${ }^{52}$ The deconvolution of the O 1s spectrum revealed three different peaks (Figure 3D). The most intense peak at $533.4 \mathrm{eV}$ corresponds to the oxygen in ether $(\mathrm{C}-\mathrm{O}-\mathrm{C})$, while the peaks at 531.7 and $535.5 \mathrm{eV}$ originate from the $\mathrm{S}=\mathrm{O}$ and $\mathrm{C}=\mathrm{O}$ bonds, respectively. ${ }^{53}$ These data are consistent with the formation of PEDOT on $\mathrm{Fe}_{3} \mathrm{O}_{4}$ nanoparticles using PIL as a linker.

A chemiresistive sensor was fabricated by depositing the PEDOT-PIL@ $\mathrm{Fe}_{3} \mathrm{O}_{4}$ nanostructures onto interdigitated microelectrodes. The performance of the sensors, during this exposure for analytes including ethanol, methanol, acetone, benzene, and toluene, was evaluated in terms of their sensor response, which is defined (see Equation 1) as the relative resistance change $\left(A_{R}=\Delta R / R_{O}\right)$. Upon exposure to the analyte vapors, the sensor showed a sharp increase in resistance with analyte's sorption and exhibited a positive vapor coefficient. The resistance of each of the sensors returned to its initial value when the analyte vapor flow was turned off and the $\mathrm{N}_{2}$
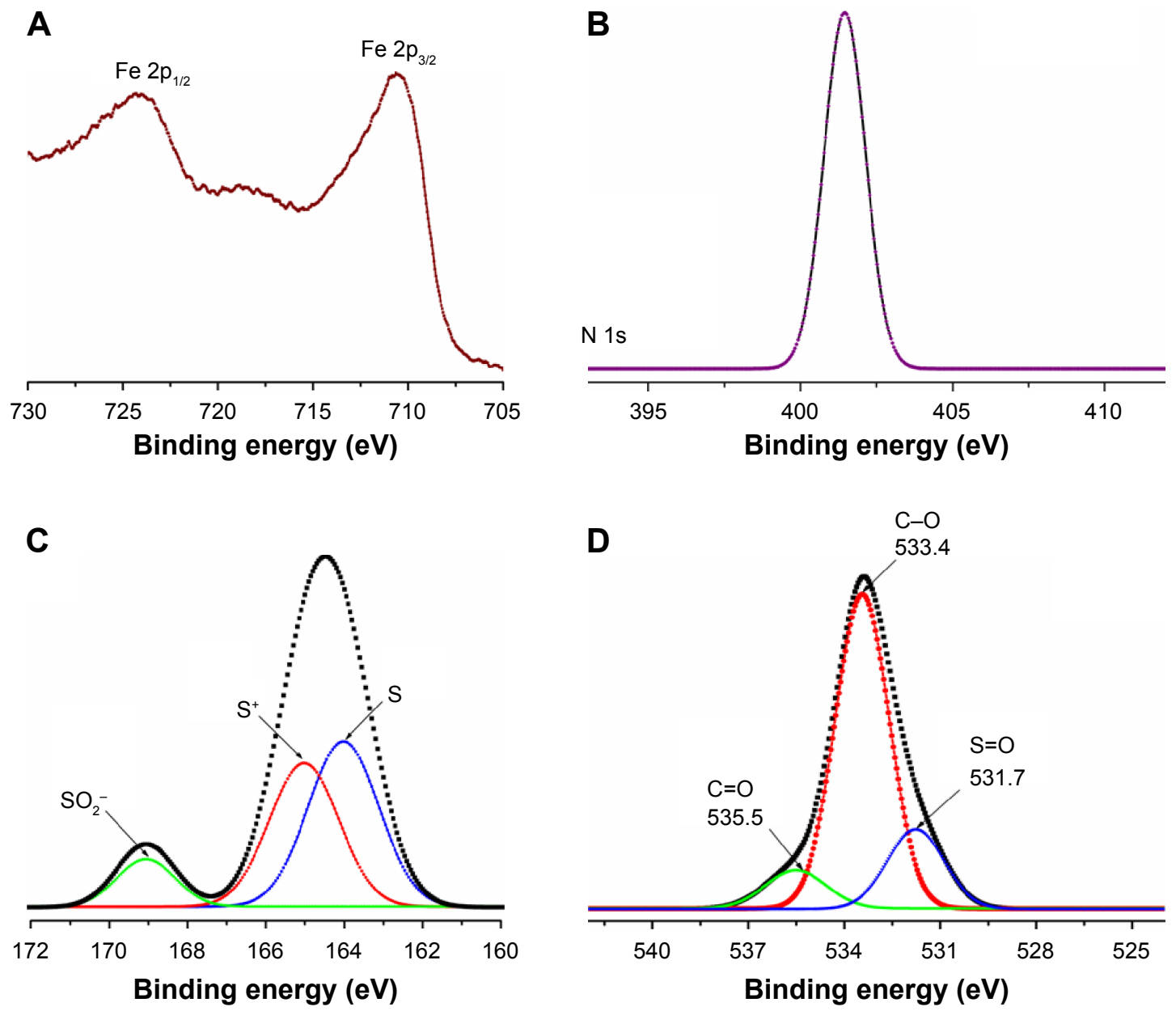

Figure 3 XPS spectra.

Notes: (A) Fe 2p and (B) N Is XPS spectra of the PIL-modified $\mathrm{Fe}_{3} \mathrm{O}_{4}$ nanoparticles. (C) S 2p and (D) O Is XPS spectra of the PEDOT-PIL@Fe $\mathrm{O}_{4}$ hybrid composite. Abbreviations: PEDOT, poly(3,4-ethylenedioxythiophene); PIL, polymerized ionic liquid; XPS, X-ray photoelectron spectroscopy; p, atomic " $\mathrm{p}$ " orbital; s, atomic "s" orbital. 
gas flow restored; this was indicative of a complete desorption of vapor molecules from the sensing materials and full recovery of the device. The reproducibility of the results was demonstrated for vapor exposures performed between the recovery periods. The performance of the sensor based on the PEDOT-PIL@ $@ \mathrm{Fe}_{3} \mathrm{O}_{4}$ composite was compared with that of its PEDOT-PIL-only counterpart; the nonconductive PIL@ $\mathrm{Fe}_{3} \mathrm{O}_{4}$ was excluded from the chemiresistive VOC sensing test.

Figure 4 shows the normalized sensor response of the PEDOT-PIL and PEDOT-PIL $@ \mathrm{Fe}_{3} \mathrm{O}_{4}$ channels to saturated concentrations of the different VOCs. The sensing behavior of the PEDOT-PIL@ $\mathrm{Fe}_{3} \mathrm{O}_{4}$ channels differed markedly from that of the PEDOT-PIL and varied significantly with the type of VOC molecules. In the case of the PEDOT-PIL sensors, the maximum amplitude of the signal is less than
0.22 and the electrical response to different VOCs can be written in descending order of sensitivity as: $A_{R \text { methanol }}>$ $A_{\text {Rethanol }}>A_{\text {Racetone }}>A_{\text {Rbenzene }}>A_{\text {Rtoluene }}($ Figure $4 \mathrm{~A})$. The interactions between the sensor arrays and vapor molecules lead to changes in both the carrier density and mobility. The conformation of the conductive polymer chains can also be modified owing to the strong interaction with certain organic solvents, which may lead to changes in the conductivity. ${ }^{54-56}$ Moreover, the diffusion of analytes into the composites sensor may also affect the doping activity of the PIL on PEDOT, thereby leading to an increase in the resistance.

The sensitivity of the sensors made with PEDOTPIL@ $\mathrm{Fe}_{3} \mathrm{O}_{4}$ channels (Figure 4B) increased with increasing amplitude. The response of the PEDOT-PIL@ $\mathrm{Fe}_{3} \mathrm{O}_{4}$ sensor to VOC analytes can be written in descending
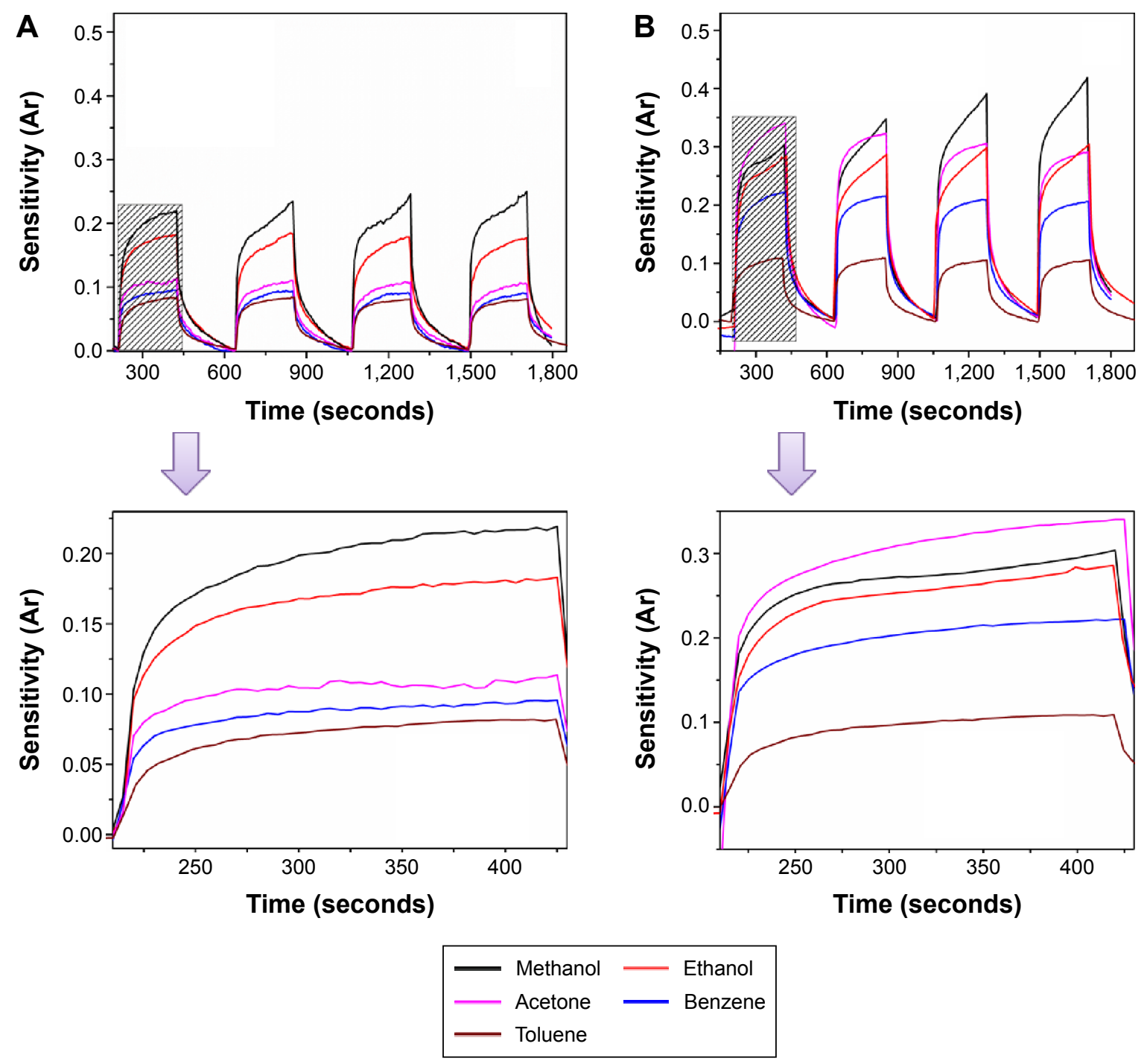

Figure 4 Sensing response of the (A) PEDOT-PIL and (B) PEDOT-PIL@Fe $\mathrm{O}_{4}$ composite to VOC analytes.

Abbreviations: Ar, relative amplitude of the electrical signals; PEDOT, poly(3,4-ethylenedioxythiophene); PIL, polymerized ionic liquid; VOC, volatile organic compound. 
order as $A_{\text {Rmethanol }}>A_{\text {Racetone }}>A_{\text {Rethanol }}>A_{R \text { benzene }}>A_{\text {Rtoluene }}$ The differing sensing behaviors of the PEDOT-PIL and PEDOT-PIL@ $\mathrm{Fe}_{3} \mathrm{O}_{4}$ channels are indicative of the different molecular interaction between these sensing materials and the VOCs; this implies that the hybridization of $\mathrm{Fe}_{3} \mathrm{O}_{4}$ and PEDOT plays an important role in increasing the sensitivity and selectivity of the sensor. As shown in Figure S4, the sensitivity of the PEDOT-PIL $@ \mathrm{Fe}_{3} \mathrm{O}_{4}$ is much higher than that of PEDOT-PIL for all analyte vapors used in this study. We interpreted this result by the fact that the incorporation of $\mathrm{Fe}_{3} \mathrm{O}_{4}$ nanoparticles affects the surface area and swelling behavior of channel materials in the presence of analyte vapors. Then, the efficient swelling can trigger macroscopic resistance variation as the conducting network is easily disconnected. In addition, compared to its PEDOTPIL-only counterpart, the sensor with PEDOT-PIL@ $\mathrm{Fe}_{3} \mathrm{O}_{4}$ channels exhibited a more stable sensing curve with lower levels of noise. Therefore, the PEDOT-PIL@ $\mathrm{Fe}_{3} \mathrm{O}_{4}$ sensor exhibited a better sensor response than its counterpart. This improved performance is likely due to an increase in the electroactive surface area of the PEDOT by incorporation of $\mathrm{Fe}_{3} \mathrm{O}_{4}$ nanoparticles, which allow for an enhanced charge-exchange rate and dissipation of the noise by electron circulation. ${ }^{52}$ It is also observed that the magnetic properties of $\mathrm{Fe}_{3} \mathrm{O}_{4}$ nanoparticles would be responsible for the reduction of noise level. ${ }^{57}$

The amplitude of the response, $A_{R}$, depends on the molecular interaction between the sensing materials and the VOC analyte molecules, as expressed in Equation 2:

$$
A_{R}=a e^{\frac{b}{\chi_{12}}}
$$

where $a$ and $b$ are constants, and $\chi_{12}$ is the Flory-Huggins intermolecular interaction parameter derived from Equation 3:

$$
\chi_{12}=\frac{V_{m}\left(\delta_{T P o l}-\delta_{T a n a}\right)^{2}}{R T}
$$

where $V_{m}$ is the molar volume of the analyte molecules $\left(\mathrm{cm}^{3} \cdot \mathrm{mol}^{-1}\right) ; R=8.314 \mathrm{~J} \cdot \mathrm{K}^{-1} \cdot \mathrm{M}^{-1} ; T$ is absolute temperature in Kelvin; $\delta_{T P_{0 l}}$ is polymer global solubility parameter $\left(\mathrm{J} \cdot \mathrm{cm}^{-3}\right)^{1 / 2}$; and $\delta_{\text {Tana }}$ is analyte global solubility parameter $\left(\mathrm{J} \cdot \mathrm{cm}^{-3}\right)^{1 / 2}$.

In general, the interphase swelling of the conducting polymer composite increases with decreasing $\chi_{12}$, thereby leading to an increase in the resistance, and the relative amplitude $A_{R}$.

Figure 5A shows a plot of the sensor response toward the concentration of acetone vapor. The chemiresistive response of the conductive polymer composite sensors can be described by the Langmuir-Henry-clustering model (Equation 4), which can predict different chemiresistive behavior in a range of vapor concentrations: ${ }^{.5,59}$

$$
A_{R}=\frac{b_{L}\left(f^{\prime \prime}-f\right)}{1+b_{L} f}+k_{H} f+\left(f-f^{\prime}\right) f^{n^{\prime}}
$$

where $b_{L}$ is the Langmuir affinity constant, $k_{H}$ the Henry's solubility coefficient, $n^{\prime}$ the number of vapor molecules per cluster, and $f$ the solvent fraction; $f^{\prime}$ and $f^{\prime \prime}$ correspond to transitions between different regimes of diffusion.

In Figure 5A, the sensor gives responses proportional to the analyte concentration in the ppm range, suggesting that the dominant mode that can take place in this sensor is Henry's diffusion. Figure 5B compares the response of the PEDOT-PIL@ $\mathrm{Fe}_{3} \mathrm{O}_{4}$ and PEDOT-PIL sensors to the target VOC; ie, acetone at a concentration of $1 \mathrm{ppm}$. Acetone is a typical biomarker for lung cancer since, owing to metabolic disorders, it is found in concentrations of $>1.5 \mathrm{ppm}$ in the exhaled breath of lung cancer patients. ${ }^{60-63}$ Therefore, the improved sensing performance to acetone vapors is essential to lung cancer diagnosis. In terms of amplitude of the signal, the PEDOT-PIL@ $\mathrm{Fe}_{3} \mathrm{O}_{4}$ sensor exhibited a 38.8\% higher response to acetone vapor than its PEDOT-PIL counterpart. Moreover, the sensor exhibited a stable sensing curve, indicative of low noise and high signal-to-noise ratio (SNR). The noise of the sensor can be calculated as the root-mean-square deviation (RMS) of the relative resistance change from the baseline. ${ }^{64}$ The standard deviation in the baseline resistance, prior to acetone exposure, was taken from ten data points, as shown in Figure 5C.

A polynomial fit to the plotted data provides a curvefitting equation and the statistical parameters for calculating the data-point range:

$$
V_{x^{2}}=\sum\left(y_{i}-y\right)^{2}
$$

where $y_{i}$ is the measured data point and $y$ is the corresponding value calculated from the curve-fitting equation. The RMS noise is calculated from the following equation:

$$
R M S_{\text {noise }}=\sqrt{\frac{V_{x^{2}}}{N}}
$$

where $N$ is the number of data points used in the curve fitting.

Noise levels of 0.00240 and 0.00217 (Figure 5D) calculated for the PEDOT-PIL and PEDOT-PIL@ $\mathrm{Fe}_{3} \mathrm{O}_{4}$ sensors, respectively, revealed that the PEDOT-PIL@ $\mathrm{Fe}_{3} \mathrm{O}_{4}$ resulted 


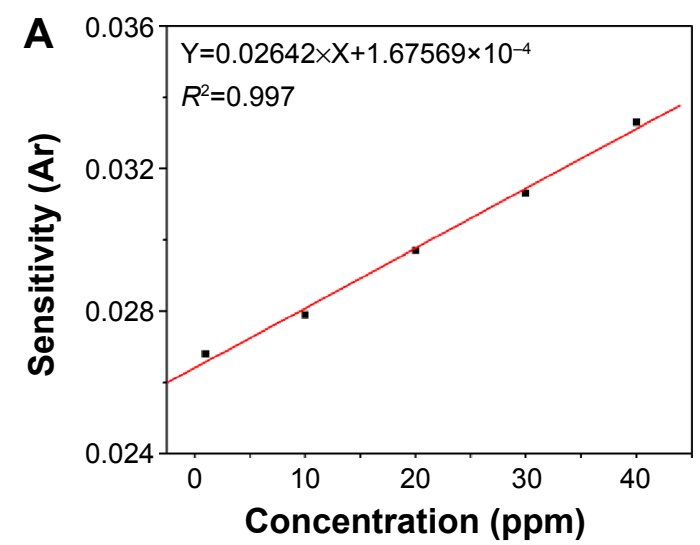

C

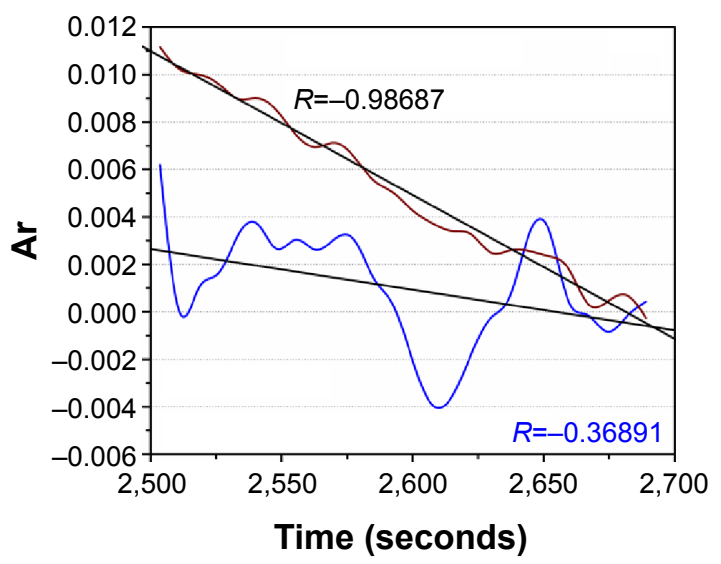

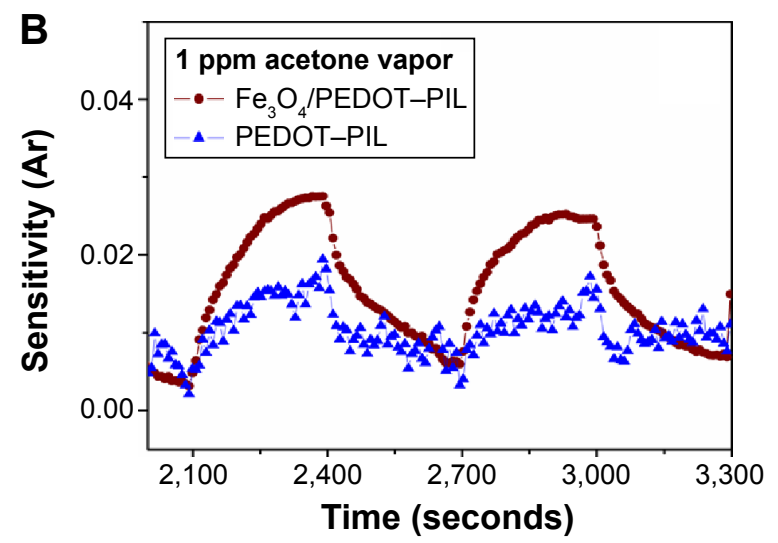

D RMS noise

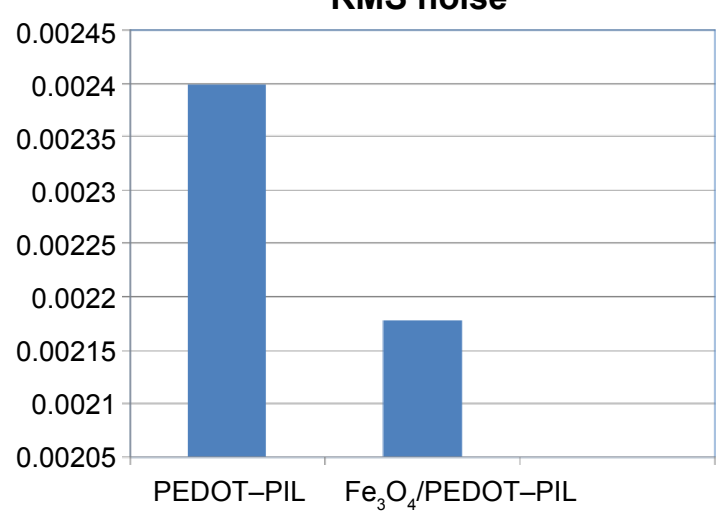

Figure 5 Performance of PEDOT-PIL@ $\mathrm{Fe}_{3} \mathrm{O}_{4}$ sensor.

Notes: (A) Calibration of PEDOT-PIL@ $\mathrm{Fe}_{3} \mathrm{O}_{4}$ sensor to concentration of acetone vapor; (B) sensing response of the PEDOT-PIL@Fe $\mathrm{O}_{4}$-composite-based and PEDOTPIL sensors to acetone vapor at a concentration of I ppm; (C) the standard deviation in the baseline resistance after exposing to acetone; (D) comparison of the RMS noise of the PEDOT-PIL and PEDOT-PIL@Fe $\mathrm{O}_{4}$ sensors.

Abbreviations: Ar, relative amplitude of the electrical signals; PEDOT, poly(3,4-ethylenedioxythiophene); PIL, polymerized ionic liquid; RMS, root-mean-square deviation; ppm, parts per million.

in an $11 \%$ reduction in the noise associated with the sensor response. Therefore, the PEDOT-PIL@ $\mathrm{Fe}_{3} \mathrm{O}_{4}$-based sensor arrays exhibit more reliable response to acetone vapor at concentrations in the ppm range. In addition, according to the The International Union of Pure and Applied Chemistry definition, the signal is considered to be a true signal when its SNR equals 3. ${ }^{64}$ Thus, the detection limit (DL) can be extrapolated from the linear calibration curve by using the following equation:

$$
\mathrm{DL}(\mathrm{ppm})=3 \frac{R M S}{\text { slope }}
$$

The detection limit of the PEDOT-PIL@ $\mathrm{Fe}_{3} \mathrm{O}_{4}$-based sensor is estimated as $257 \mathrm{ppb}$, which is two-times lower than the PEDOT-PIL-only sensor (515 ppb). These results suggest that the PEDOT-PIL@ $\mathrm{Fe}_{3} \mathrm{O}_{4}$-based sensor has significant potential for use in the detection of VOC biomarkers for lung cancer diagnosis.

\section{Conclusion}

We demonstrated a chemiresistive sensor based on coreshell hybridized nanostructures of $\mathrm{Fe}_{3} \mathrm{O}_{4}$ and PEDOT for the efficient detection of VOC biomarkers. These hybrid nanostructures were synthesized by using PILs as surfacefunctionalizing materials, which prevented the aggregation of $\mathrm{Fe}_{3} \mathrm{O}_{4}$ nanoparticles and promoted the formation of PEDOT on the $\mathrm{Fe}_{3} \mathrm{O}_{4}$ surface. The resulting PEDOT-PIL@ $\mathrm{Fe}_{3} \mathrm{O}_{4}$ hybrids were used as sensing channel materials to detect various VOC vapors such as methanol, ethanol, acetone, benzene, and toluene. These sensors exhibited a remarkable sensing response (ie, high sensitivity, selectivity, and SNR) to the VOC vapors. In addition, the PEDOT-PIL $@ \mathrm{Fe}_{3} \mathrm{O}_{4}$ 
sensor exhibited a significantly higher sensing response to $1 \mathrm{ppm}$ acetone vapor analyte, ie, a $38.8 \%$ higher sensitivity and an 11\% lower noise level, than the PEDOT-PIL sensor. The sensor presented in this work exhibited high sensitivity with a detection limit in the ppb range and reliable sensing behavior to VOC biomarkers; this reliable sensing behavior is essential to the early diagnosis of lung cancer.

\section{Acknowledgments}

This research was supported by the R\&D Program of the Society of the National Research Foundation (NRF) funded by the Ministry of Science, ICT and Future Planning (grant number 2013M3C8A3078806). The authors are also grateful for the grant of the University of Adelaide, South Australia.

\section{Disclosure}

The authors report no conflicts of interest in this work.

\section{References}

1. Jemal A, Siegel R, Ward E, et al. Cancer statistics. CA Cancer J Clin. 2008;58:71-96.

2. Peng G, Tisch U, Adams O, et al. Diagnosing lung cancer in exhaled breath using gold nanoparticles. Nat Nanotechnol. 2009;4:669-673.

3. Xu ZQ, Broza YY, Ionsecu R, et al. A nanomaterial-based breath test for distinguishing gastric cancer from benign gastric conditions. $\mathrm{Br}$ J Cancer. 2013;108:941-950.

4. Haick H, Broza YY, Mochalski P, Ruzsanyi V, Amann A. Assessment, origin, and implementation of breath volatile cancer markers. Chem Soc Rev. 2004:43:1423-1449.

5. de Lacy Costello B, Amann A, Al-Kateb H, et al. A review of the volatiles from the healthy human body. J Breath Res. 2014;8:014001.

6. Broza YY, Zuri L, Haick H. Combined volatolomics for monitoring of human body chemistry. Sci Rep. 2014;4:4611.

7. Chatterjee S, Castro M, Feller JF. An e-nose made of carbon nanotube based quantum resistive sensors for the detection of eighteen polar/nonpolar VOC biomarkers of lung cancer. J Mater Chem B. 2013;1:4563-4575.

8. Nag S, Duarte L, Bertrand E, et al. Ultrasensitive QRS made by supramolecular assembly of functionalized cyclodextrins and graphene for the detection of lung cancer VOC biomarkers. J Mater Chem B. 2014;2 6571-6579.

9. Shin J, Choi SJ, Lee I, et al. Thin-wall assembled $\mathrm{SnO}_{2}$ fibers functionalized by catalytic Pt nanoparticles and their superior exhaled-breathsensing properties for the diagnosis of diabetes. Adv Funct Mater. 2013; 23:2357-2367.

10. Gordon SM, Szidon JP, Krotoszynski BK, Gibbons RD, O’Neill HJ. Volatile organic compounds in exhaled air from patients with lung cancer. Clin Chem. 1985;31(8):1278-1282.

11. Miekisch W, Fuchs P, Kamysek S, Neumann C, Schubert JK. Assessment of propofol concentrations in human breath and blood by means of HS-SPME-GC-MS. Clin Chim Acta. 2008;395:32-37.

12. Phillips M, Gleeson K, Hughes JM, et al. Volatile organic compounds in breath as markers of lung cancer: a cross-sectional study. Lancet. 1999;353:1930-1933.

13. Kim KH, Jahan SA, Kabir E. A review of breath analysis for diagnosis of human health. Trends Analyt Chem. 2012;33:1-8.

14. Peled N, Ionescu R, Nol P, et al. Detection of volatile organic compounds in cattle naturally infected with Mycobacterium bovis. Sens Actuators B Chem. 2012;171-172:588-594.
15. Smith D, Wang T, Sulé-Suso J, Spane P, El-Haj A. Quantification of acetaldehyde released by lung cancer cells in vitro using selected ion low tube mass spectrometry. Rapid Commun Mass Spectrom. 2003;17:845-850.

16. Amann A, Spaněl P, Smith D. Breath analysis: the approach towards clinical applications. Mini Rev Med Chem. 2007;7:115-129.

17. Yates DH, Kharitonov SA, Robbins RA, Thomas PS, Barnes PJ. Effect of a nitric oxide synthase inhibitor and a glucocorticosteroid on exhaled nitric oxide. Am J Respir Crit Care Med. 1995;152:892-896.

18. Kolle C, Gruber W, Trettnak W, et al. Fast optochemical sensor for continuous monitoring of oxygen in breath-gas analysis. Sens Actuators B Chem. 1997;38:141-149.

19. Giubileo G. Medical diagnostics by laser-based analysis of exhaled breath. SPIE Proceedings. 2002;4762:318-325.

20. Groves WA, Zellers ET, Frye GC. Analyzing organic vapors in exhaled breath using a surface acoustic wave sensor array with preconcentration: Selection and characterization of the preconcentrator adsorbent. Anal Chim Acta. 1998;371:131-143.

21. Arshak K, Moore E, Lyons GM, Harris J, Clifford S. A review of gas sensors employed in electronic nose applications. Sensor Review. 2004; 24:181-198

22. Toda K, Li J, Dasgupta PK. Measurement of ammonia in human breath with a liquid-film conductivity sensor. Anal Chem. 2006;78: 7284-7291.

23. Amorim LC, de L Cardeal Z. Breath air analysis and its use as a biomarker in biological monitoring of occupational and environmental exposure to chemical agents. $J$ Chromatogr B Analyt Technol Biomed Life Sci. 2007;853:1-9.

24. Kim ID, Rothschild A, Lee BH, Kim DY, Jo SM, Tuller HL. Ultrasensitive chemiresistors based on electrospun $\mathrm{TiO}_{2}$ nanofibers. Nano Lett. 2006;6:2009-2013.

25. Persaud K, Dodd G. Analysis of discrimination mechanisms in the mammalian olfactory system using a model nose. Nature. 1982;299: 352-355.

26. Krasteva N, Fogel Y, Bauer RE, Müllen K, Joseph Y, Matsuzawa N, Yasuda A, Vossmeyer T. Vapor sorption and electrical response of Au-nanoparticle/dendrimer composites. Adv Funct Mater. 2007;17: $881-888$.

27. Joseph Y, Guse B, Vossmeyer T, Yasuda A. Gold nanoparticle/organic networks as chemiresistor coatings: the effect of film morphology on vapor sensitivity. J Phys Chem C. 2008;112:12507-12514.

28. Neaves PI, Hatfield JV. A new generation of integrated electronic noses. Sens Actuators B Chem. 1995;27:223-231.

29. Lee JS, Jun J, Shin DH, Jang J. Urchin-like polypyrrole nanoparticles for highly sensitive and selective chemiresistive sensor application. Nanoscale. 2014;6:4188-4194.

30. Park E, Kwon OS, Park SJ, Lee JS, You S, Jang J. One-pot synthesis of silver nanoparticles decorated poly(3,4-ethylenedioxythiophene) nanotubes for chemical sensor applicaion. $J$ Mater Chem. 2012;22: $1521-1526$.

31. Kwon OS, Park SJ, Lee JS, et al. Multidimensional conducting polymer nanotubes for ultrasensitive chemical nerve agent sensing. Nano Lett. 2012;12:2797-2802.

32. Severin EJ, Doleman BJ, Lewis NS. An investigation of the concentration dependence and response to analyte mixtures of carbon black/ insulating organic polymer composite vapor detectors. Anal Chem. 2000;72:658-668.

33. Kong J, Franklin NR, Zhou C, et al. Nanotube molecular wires as chemical sensors. Science. 2000;287:622-625.

34. Lim JH, Park J, Oh EH, Ko HJ, Hong S, Park TH. Nanovesicle-based bioelectronic nose for the diagnosis of lung cancer from human blood. Adv Healthc Mater. 2014;3:360-366.

35. Kim TH, Lee SH, Lee J, Song HS, Oh EH, Park TH, Hong S. Wide contact structures for low-noise nanochannel devices based on a carbon nanotube network. Adv Mater. 2009;21:91-94.

36. Vedala H, Sorescu DC, Kotchey GP, Star A. Chemical sensitivity of graphene edges decorated with metal nanoparticles. Nano Lett. 2011;11:2342-2347. 
37. Tien HW, Huang YL, Yang SY, Wang JY, Ma CCM. The production of graphene nanosheets decorated with silver nanoparticles for use in transparent, conductive films. Carbon. 2011;49:1550-1560.

38. Hieu NV, Duc NAP, Trung T, Tuan MA, Chien ND. Gas-sensing properties of tin oxide doped with metal oxides and carbon nanotubes: A competitive sensor for ethanol and liquid petroleum gas. Sens Actuators B Chem. 2010;144:450-456.

39. Joseph Y, Guse B, Nelles G. Aging of 1, $\omega$-alkyldithiol interlinked Au-nanoparticle networks. Chem Mater. 2009;21:1670-1676.

40. Sun YF, Liu SB, Meng FL, et al. Metal oxide nanostructures and their gas sensing properties. Sensors (Basel). 2012;12(3):2610-2631.

41. Khoang ND, Trung DD, Duy NV, Hoa ND, Hieu NV. Design of $\mathrm{SnO}_{2} /$ $\mathrm{ZnO}$ hierarchical nanostructures for enhanced ethanol gas-sensing performance. Sens Actuators B Chem. 2012;174:594-601.

42. Hieu NV, Van PTH, Nhan LT, Duy NV, Hoa ND. Giant enhancement of $\mathrm{H}_{2} \mathrm{~S}$ gas response by decorating n-type $\mathrm{SnO}_{2}$ nanowires with p-type NiO nanoparticles. Appl Phys Lett. 2012;101:253106.

43. Cho S, Lee JS, Jun J, Jang J. High-sensitivity hydrogen gas sensors based on Pd-decorated nanoporous poly(aniline-co-aniline-2-sulfonic acid): poly(4-styrenesulfonic acid). J Mater Chem A. 2014;2:1955-1966.

44. Shin S, Jang J. Thiol containing polymer encapsulated magnetic nanoparticles as reusable and efficiently separable adsorbent for heavy metal ions. Chem Commun (Camb). 2007;(41):4230-4232.

45. Callaway MK, Ochoa JM, Perez EE, Ulrich PE, Alocilja EC, Vetrone SA. Investigation of the toxicity of amine-coated, carboxylcoated and polyaniline-coated $\mathrm{FeO}$ magnetic nanoparticles in Caenorhabditis elegans. Biosens Bioelectron. 2013;4(5).

46. Yuk JS, Rose J, Alocilja EC. Characterization of polyaniline-coated magnetic nanoparticles for application in a disposable membrane strip biosensor. The European Physical Journal Applied Physics. 2010;50: 11401-11406.

47. Zhao B, Nan Z. Preparation of stable magnetic nanofluids containing Fe3O4@PPy nanoparticles by a novel one-pot route. Nanoscale Res Lett. 2011;6:230.

48. Tahmasebi E, Yamini Y, Seidi S, Rezazadeh M. Extraction of three nitrophenols using polypyrrole-coated magnetic nanoparticles based on anion exchange process. J Chromatogr A. 2013;1314:15-23.

49. Kim TY, Lee TH, Kim JE, Kasi RM, Sung CSP, Suh KS. Organic solvent dispersion of poly(3,4-ethylenedioxythiophene) with the use of polymeric ionic liquid. J Polym Sci A Polym Chem. 2008;46:6872-6879.

50. Tung TT, Kim TY, Shim JP, Yang WS, Kim H, Suh KS. Poly(ionic liquids)-stabilized graphene sheets and their hybrid poly $(3,4-$ ethylenedioxythiophene). Org Electron. 2011;12:2215-2224.

51. Chandra V, Park J, Chun Y, Lee JW, Hwang IC, Kim KS. Waterdispersible magnetic-reduced graphene oxide composite for arsenic removal. ACS Nano. 2010;4:3979-3986.
52. Tung TT, Castro M, Kim TY, Suh KS, Feller JF. Graphene quantum resistive sensing skin for the detection of alteration biomarkers. J Mater Chem. 2012;22:21754-21766.

53. Kim T, Tung TT, Lee T, Kim J, Suh KS. Poly(ionic liquid)-mediated hybridization of single-walled carbon nanotubes and conducting polymers. Chem Asian J. 2010;5:256-260.

54. Janata J, Josowicz M. Conducting polymers in electronic chemical sensors. Nat Mater. 2003;2:19-24.

55. Bai H, Shi G. Gas sensors based on conducting polymers. Sensors. 2007; 7:267-307.

56. Heeger AJ. Semiconducting and Metallic Polymers: The Fourth Generation of Polymeric Materials (Nobel Lecture) Copyright(c) The Nobel Foundation 2001. We thank the Nobel Foundation, Stockholm, for permission to print this lecture. Angew Chem Int Ed Engl. 2001;40: 2591-2611.

57. Tung TT, Castro M, Pillin I, Kim TY, Suh KS, Feller JF. Graphene$\mathrm{Fe}_{3} \mathrm{O}_{4} / \mathrm{PIL}-\mathrm{PEDOT}$ for the design of sensitive and stable quantum chemo-resistive VOC sensors. Carbon. 2014;74:104-112.

58. Feller JF, Lu J, Zhang K, et al. Novel architecture of carbon nanotube decorated poly(methyl methacrylate) microbead vapour sensors assembled by spray layer by layer. J Mater Chem. 2011;21:4142-4149.

59. Lu J, Kumar B, Castro M, Feller JF. Vapour sensing with conductive polymer nanocomposites (CPC): polycarbonate-carbon nanotubes transducers with hierarchical structure processed by spray layer by layer. Sens Actuators B Chem. 2009;140:451-460.

60. Kim NH, Choi SJ, Yang DJ, Bae J, Park J, Kim ID. Highly sensitive and selective hydrogen sulfide and toluene sensors using Pd functionalized $\mathrm{WO}_{3}$ nanofibers for potential diagnosis of halitosis and lung cancer. Sens Actuators B Chem. 2014;193:574-581.

61. Lee I, Choi SJ, Park KM, et al. The stability, sensitivity and response transients of $\mathrm{ZnO}, \mathrm{SnO}_{2}$ and $\mathrm{WO}_{3}$ sensors under acetone, toluene and $\mathrm{H}_{2} \mathrm{~S}$ environments. Sens Actuators B Chem. 2014;197:300-307.

62. Choi SJ, Choi C, Kim SJ, Cho HJ, Jeon S, Kim ID. Facile synthesis of hierarchical porous $\mathrm{WO}_{3}$ nanofibers having $1 \mathrm{D}$ nanoneedles and their functionalization with non-oxidized graphene flakes for selective detection of acetone molecules. RSC Adv. 2015;5:7584-7588.

63. Peng G, Hakim M, Broza YY, et al. Detection of lung, breast, colorectal, and prostate cancers from exhaled breath using a single array of nanosensors. Br J Cancer. 2010;103:542-551.

64. Li J, Lu Y, Ye Q, Cinke M, Han J, Mayyappan M. Carbon nanoture sensors for gas and organic vapor detection. Nano Lett. 2003;3:929-933.

65. Hakim M, Broza YY, Barash O, et al. Volatile organic compounds of lung cancer and possible biochemical pathways. Chem Rev. 2012;11(11)2:5949. 


\section{Supplementary materials}

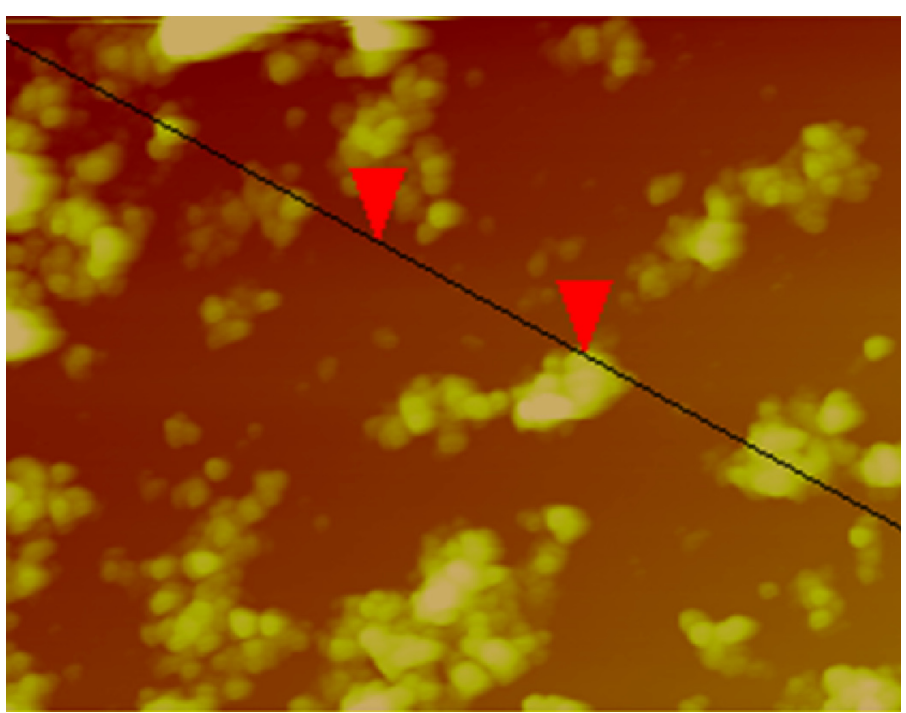

\section{Section analysis}

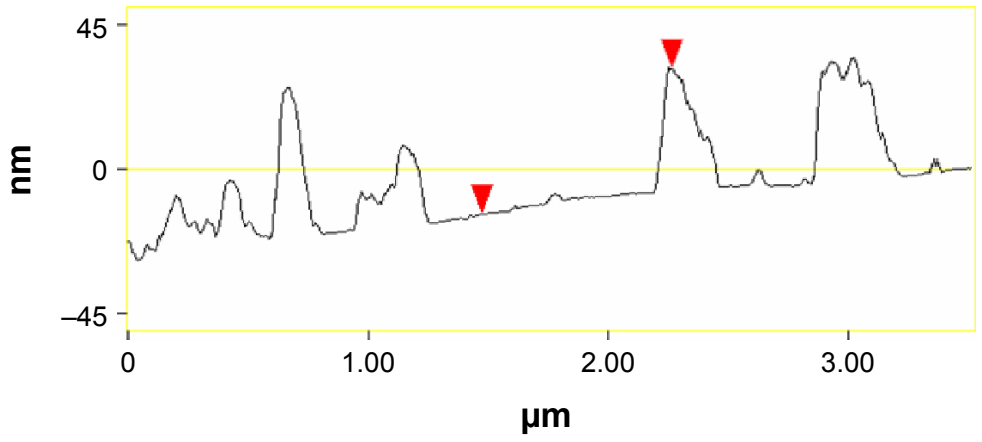

Figure SI AFM image of the PEDOT-PIL@ $\mathrm{Fe}_{3} \mathrm{O}_{4}$, showing that the magnetic NPs are fully covered by conducting polymer, PEDOT. Note: The red arrows represent the position where the scan line cross the sample.

Abbreviations: AFM, atomic force microscopy; NPs, nanoparticles; PEDOT, poly(3,4-ethylenedioxythiophene); PIL, polymerized ionic liquid.

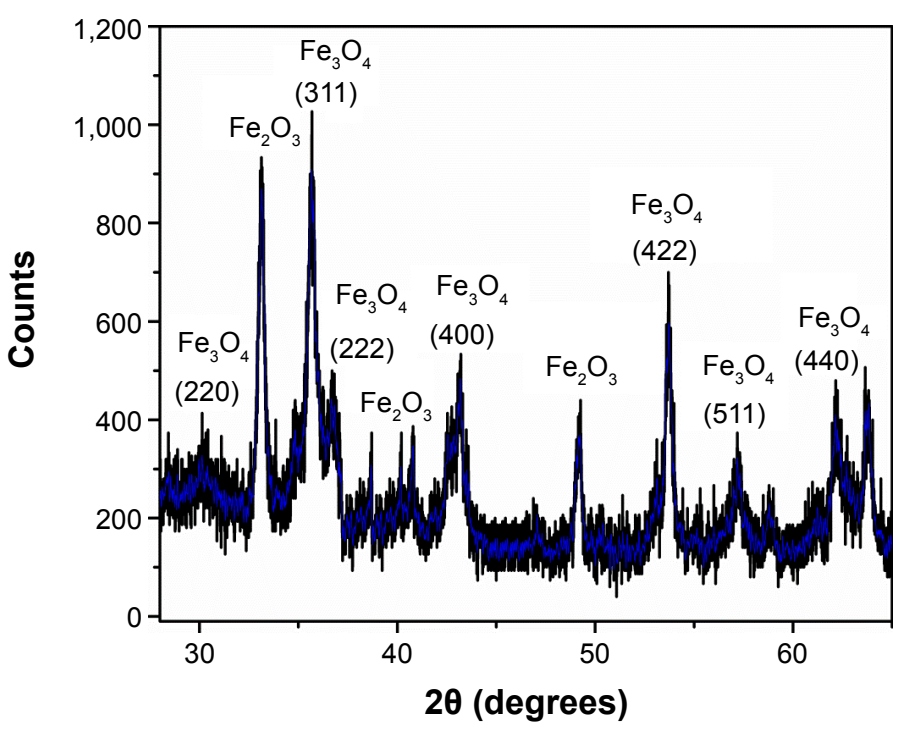

Figure S2 An X-ray diffraction pattern of the synthesized $\mathrm{Fe}_{3} \mathrm{O}_{4}$ nanoparticles modified with PIL. Abbreviation: PIL, polymerized ionic liquid. 


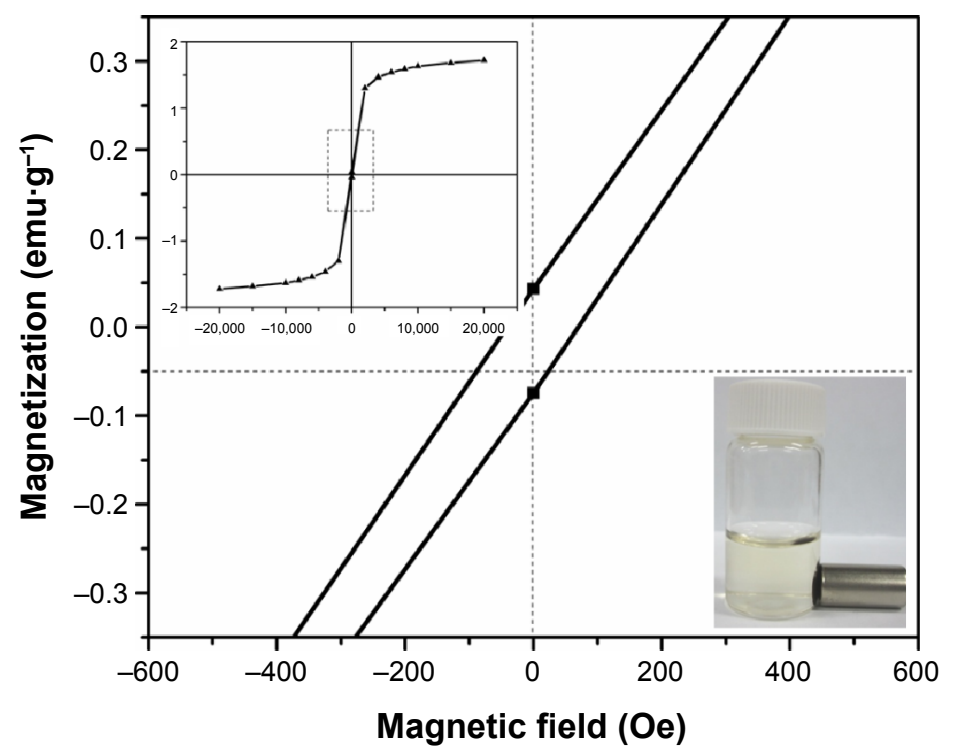

Figure S3 Zoom out on hysteresis loops showing the saturation of magnetization.

Notes: Inset, top left: the magnetization curves as a function of applied magnetic field of $\mathrm{Fe}_{3} \mathrm{O}_{4} @ P I L ;$ bottom right: digital photo showing magnetic response to an external field. Abbreviation: PIL, polymerized ionic liquid.

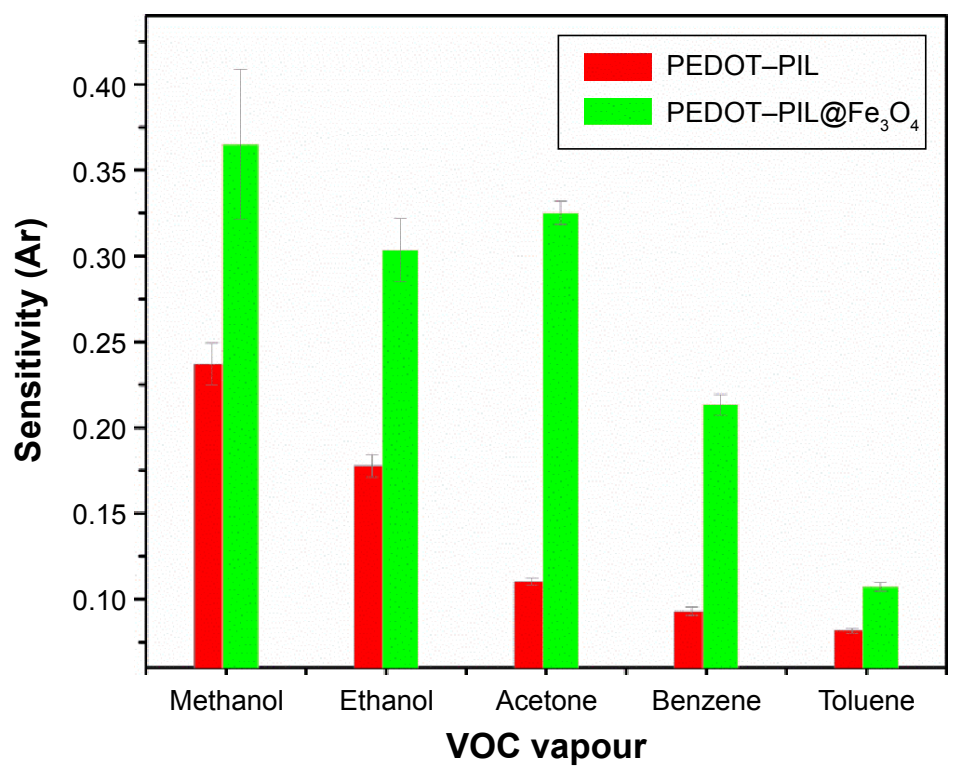

Figure S4 Comparison of the selectivity of the PEDOT-PIL and PEDOT-PIL@ $\mathrm{Fe}_{3} \mathrm{O}_{4}$ sensors toward a set of VOC biomarkers.

Abbreviations: Ar, relative amplitude of the electrical signals; PEDOT, poly(3,4-ethylenedioxythiophene); PIL, polymerized ionic liquid; VOC, volatile organic compound.

\section{Publish your work in this journal}

The International Journal of Nanomedicine is an international, peerreviewed journal focusing on the application of nanotechnology in diagnostics, therapeutics, and drug delivery systems throughout the biomedical field. This journal is indexed on PubMed Central, MedLine, CAS, SciSearch ${ }^{\circledR}$, Current Contents ${ }^{\circledR} /$ Clinical Medicine,
Journal Citation Reports/Science Edition, EMBase, Scopus and the Elsevier Bibliographic databases. The manuscript management system is completely online and includes a very quick and fair peer-review system, which is all easy to use. Visit http://www.dovepress.com/ testimonials.php to read real quotes from published authors. 